\title{
Carta à performer Eleonora Fabião: o que pode um corpo que sofre
}

\section{Letter to the performer Eleonora Fabião: what can a body that suffers}

Flávia Naves ${ }^{1}$ 


\section{Resumo}

Nesta carta escrita à performer Eleonora Fabião, relato a criação e execução do que ela chama de "programa performativo" como uma ferramenta de apropriação do meu corpo e das feridas que nele se inscrevem. Partindo da definição de David Lapoujade para um "corpo que não aguenta mais", e desejando a criação de um "corpo sem órgãos" proposta por Gilles Deleuze e Félix Guattari, aposto num corpo performativo como aquele que sabe se proteger das "feridas grosseiras" sem cair em uma "queda suicida ou demente". Analiso a realização da performance Vodu como um "motor de experiência" que, ao evocar a potência de um corpo exposto às feridas, recusa deixar de sentir.

Palavras-chave: Corpo; ferida; programa performativo; performance.

\section{Abstract}

In this letter to the performer Eleonora Fabião, I report the creation and execution of what she calls "performative program" as an appropriation tool of my body and of the wounds that are inscribed in it. Starting from the definition of David Lapoujade for a "body that cannot take anymore", and wishing to create a "body without organs" proposed by Gilles Deleuze and Felix Guattari, I suggest a performative body as a kind of body who knows to protect himself from the "gross wounds" without falling into a "suicidal or insane fall." I analyze the realization of "Vodou" performance as an "experience motor" that evokes the power of a body exposed to the wounds and its refusing in leting to feel.

Keywords: Body; wound; performative program; performance. 
Rio de Janeiro, 21 de março de 2016.

Eleonora, minha muito querida, estou há meses para te escrever, quero muito te contar.

Lembra do programa performativo Vodu que eu executei quando da minha qualificação no mestrado? Foi no dia 03 de julho do ano passado, uma sexta-feira, dentro da sala InterArtes no Instituto de Artes e Comunicação da UFF.

Elaborei uma ação para que eu pudesse encarnar a Figura do Vodu da cidade do Rio de Janeiro, tal qual o boneco de pano em que nele geralmente se espetam agulhas a fim de que a pessoa pelo boneco representada sofra o que nele é feito, eu disponibilizei o meu corpo para ser o boneco vodu da cidade. Tudo que em meu corpo fosse feito no momento da performance, seria sentido no corpo da cidade. Com uma lâmina de barbear, fiz cortes por todo o meu corpo nu (29 cortes ao todo), acompanhando as linhas que eu você, Andrêas, Ítala, Jorge, Mariana e Laura nele desenhamos com canetas marcador permanente da cor preta. Ao fazer do meu corpo - Vodu da cidade, as linhas nele desenhadas se fizeram mais que traços, se fizeram canais de conexão direta entre o meu corpo e o corpo da cidade. As linhas em meu corpo traçadas eram como veias da cidade obstruídas, inflamadas, necrosadas, feridas grosseiras tornadas visíveis pelo preto dos traços neste e deste meu corpocidade, cuja carne é diariamente judiada, abatida, esfolada por tantas e diversas formas de poder, por tantas e diversas manifestações de machismo, preconceito, sexismo, racismo, por tanto descaso público, corrupção generalizada, matança desenfreada, panelaço, privilégio de ricaço, golpe de estado gerando desamor e violência sem pudor.

Foi para fazer contato corpo a corpo com o tecido inflamado dessa nossa carioca capital e assim abrir caminhos entre as feridas, que a lâmina passou fina na minha pele-cinza-asfalto, fazendo sangrar feridas grosseiras a fim de abri-las as mais sutis.

É o filósofo francês David Lapoujade quem vai nos dizer em seu "O corpo que não aguenta mais" sobre a diferença entre a ferida grosseira e a sutil: da primeira devemos nos proteger, mas à segunda devemos nos abrir, pois que a potência de um corpo se mede pelo grau de exposição às feridas mais sutis:

A potência do corpo (aquilo que ele pode) se mede pela sua exposição aos sofrimentos ou às feridas. Mas Nietzsche diz: as feridas são as mais sutis. Isto quer dizer que a exposição do corpo se faz no interior dos mecanismos de defesa... e que o protegem das feridas mais grosseiras. Sutil, aqui, não quer dizer leve ou benigno, mas ao contrário, quer dizer que as defesas operam suficientemente para que eu tenha acesso à profundeza e à violência de uma ferida sutil - ou, inversamente, que eu tenha acesso à sutileza que esconde uma ferida grosseira. (Lapoujade, 2002, p.87-88)

Cortes feitos, feridas abertas, vesti uma calça e uma camisa de linho da cor branca em homenagem ao dia de Oxalá. O branco da roupa no contato com a pele agora cinza-sangue ganhou logo pequenas manchas avermelhadas. No pescoço vesti o colar-guia da cor branca e no pé sandálias havaianas. A Figura do Vodu da cidade do Rio de Janeiro estava montada e eu então autorizada a me lançar por suas ruas, praças e avenidas. Protegida das feridas grosseiras eu estava pronta a encarar a potência de uma ferida sutil. 
Hoje, o homem que sofre precisa da sorte muito rara de encontrar um espaço desmobilizado (espaço de amizade) para autorizar a dor e desvendar o que ela sinaliza. Fora dessas condições, ele é necessariamente devolvido ao regime autobiográfico com uma ou duas costuras na ferida e mais um ou dois bálsamos neuroquímicos para parar de doer. Assim, remendado, segue a vida sem se apropriar de si mesmo, dublando-se em termos de competência e trabalho, isto é, conforme a identidade pré-definida pela moldura epocal e pela gaiola da vez, e morre a morte dos supérfluos, dos que desconhecem a narrativa-efetiva-da-carne, o sorriso sanguíneo da singularização. (Pessanha, 2015, p.260)

Logo após a nossa conversa sobre o exame de qualificação, você partiu de carro para o Rio de Janeiro enquanto eu e Andrêas pegamos a barca para o mesmo destino. Os cortes já não sangravam, a roupa branca restava manchada e o meu rosto um tanto desfigurado pelos variados traços da caneta de cor preta.

Ao descer das barcas, retirei os chinelos dos pés e a mochila das costas, os entreguei ao Andrêas que os colocou em sua mochila. E foi assim que eu-Vodu, de mãos livres e pés descalços, e Andrêas, de tênis e mochila, caminhamos ora lado a lado, ora um do outro mais afastados, do Centro da cidade até a casa em que morávamos no bairro de Botafogo.

No encontro com a cidade cada passo era um desabafo, um suspiro e um enlace entre a sola do meu pé e o pixe do asfalto. Cada passo era um respiro profundo vindo lá debaixo, estabelecendo conexão fina e sutil entre o chão que se pisa e os tantos pés que por ele caminham. O olhar seguia atento, sem nada requerer e o corpo seguia feito ferida recém-tratada: não mais sangra, mas conserva viva a viscosidade e a latência da pele cortada.

Mediado pela Figura do Vodu, meu corpo no chão do asfalto experimentava a abertura de uma dimensão outra, a dimensão performativa. A caminhada das barcas até o bairro de Botafogo ainda era parte do programa performativo Vodu e um programa performativo como você mesma diz: "anuncia que corpos são sistemas relacionais abertos, altamente suscetíveis e cambiantes" (Fabião, 2011, p.240), pois foi assim mesmo que meu corpo naquela caminhada se anunciava corpo conectivo, atento ao que se passava entre ele e o outro, entre o outro e o meio, entre eu e nós todos, meu corpo suscetível aos mais variados encontros entre diferentes corpos e olhares.

Num dado momento do percurso, enquanto conversávamos com uma grande amiga que, sem querer, esbarramos em uma esquina no bairro do Flamengo, um cara desses da rua, pés descalços que nem eu, se abaixou diante de mim e de cócoras apontou para o corte já estancado em meu pé direito dizendo com espanto e preocupação: "o que é isso, o que aconteceu no seu pé?" Ao que eu respondi me colocando de cócoras junto a ele: "tá vendo o meu pé? Tá vendo esse chão? A gente é a mesma coisa. Eu fiz esse corte pra desobstruir uma veia inflamada dessa nossa cidade. Agora que o corte foi feito, eu e a cidade podemos respirar melhor, estamos as duas um pouco mais aliviadas." Ele não disse nada, se levantou, eu levantei em seguida e, assim que me vi de pé, ele subitamente me abraçou. Simples assim. Simples assim. Depois do abraço em tempo dilatado ele me olhou novamente e pediu para que eu prometesse não fazer mais aquilo: "não faz mais isso", ele disse, ao que eu 
respondi: "como não? Se eu não tivesse feito isso jamais teria recebido o seu abraço." E foi quando ele, com a mesma rapidez e despretensão com que me deu um abraço, me lascou um beijo na bochecha esquerda e saiu com seu corpo magro e ágil dizendo em meio ao vento: "leia mais! Você vai fazer coisas melhores!"

É...

E eu sigo, ainda hoje rindo e sorrindo...

Sabe, Eleonora, eu performo por momentos como esse, para continuar vivendo acontecimentos assim: simples e transtornantes, desobstrutores de formas rígidas e articuladores de encontros improváveis. Qual a probabilidade de um dia eu receber um beijo e um abraço espontâneo e carinhoso de um cara da rua?

Não que apenas a arte da performance seja capaz de proporcionar momentos potentes e vibrantes como este, mas como você mesma diz, é próprio da performance:

(des)habituar, (des)mecanizar, escovar a contrapelo. Trata-se de buscar maneiras alternativas de lidar com o estabelecido, de experimentar estados psicofísicos alterados, de criar situações que disseminem dissonâncias diversas: dissonâncias de ordem econômica, emocional, biológica, ideológica, psicológica, energética, espiritual, identitária, sexual, política, estética, social, racial. (Fabião, 2011, p.240)

Através da arte da performance é possível nos apropriarmos dos nossos corpos e das feridas que neles se inscrevem para então experimentar o surgimento da potência de um corpo performativo, corpo que vive o paradoxo: "de um lado, um 'Eu não aguento mais' (tudo aquilo de que devo me defender, daquilo que meu corpo sofre e me faz sofrer), do outro, um 'Eu sinto (no sentido de que nos abrimos a tudo aquilo que advém sob o regime do sutil). (Lapoujade, 2002, p.89)

O que levou um estranho da rua a vir conversar com o meu corpo de forma quase íntima? O que tornou possível a singularidade deste encontro? Suponho que ao menos dois fatores: a Figura que naquele momento me vestia e a dimensão performativa a que meu corpo se abria, dimensão esta do regime do sutil que disponibiliza o corpo ao encontro ao mesmo tempo em que o defende das feridas grosseiras.

Eleonora, existir neste meu corpo, neste meu corpo de mulher é uma ferida tão grosseira que, para me permitir à violência e à beleza de um encontro, para me abrir às feridas sutis, preciso me conectar à sua Figura. Eu preciso me vestir, me desvestir, me desnudar e me (re)cobrir. Montada a Figura, eu estou pronta para o abraço, para o beijo na bochecha e até mesmo para as palavras chulas. Montada a Figura meu corpo está apto para se expor ao sofrimento, sofrimento este que "aumenta a potência de agir dos corpos".

Ao citar Nietzsche, Lapoujade diz que o crescimento da potência de um corpo se dá "lá onde houve abundância de feridas sutis, através das quais aumenta a necessidade de apropriação." E Lapoujade continua: "a apropriação vem do fato de que o corpo não suporta a ferida (grosseira), de que ele não aguenta mais. A potência do corpo (aquilo que ele pode) se mede pela sua exposição aos sofrimentos ou às feridas. (Lapoujade, 2002, p.87)

Se para Lapoujade a potência de um corpo se mede pela sua exposição ao sofrimento é porque sofrer é condição primeira do corpo, um corpo sofre de sua exposi- 
ção ao fora, do encontro com outros corpos:

A primeira coisa, é que o sofrimento não é um estado particular do corpo, sofrer é condição primeira do corpo. Sofrer é a condição de estar exposto ao fora. Um corpo sofre de sua exposição à novidade do fora, ou seja, ele sofre de ser afetado. Como diz Deleuze, um corpo não cessa de ser submetido à erupção contínua de encontros, encontro com a luz, com o oxigênio, com os alimentos, com os sons e palavras cortantes etc. Um corpo é primeiramente encontro com outros corpos. (Lapoujade, 2002, p.86)

O que Lapoujade quer nos assegurar, Eleonora, é que a condição primeira do corpo é sofrer e se tal sofrimento leva o corpo a ser definido como "aquele que não aguenta mais", é porque talvez seja preciso compreender o que o corpo não aguenta mais para, em seguida, saber como agir a fim de encontrar potência em face desse sofrimento que é a sua própria condição.

Neste instante gostaria de te fazer um convite que, acredito eu, você não irá recusar. Peço a permissão para segurar a sua mão e te conduzir a uma espécie de túnel em que nossos corpos, ao nele entrar, serão intensamente maltratados, machucados e feridos, mas que, ao sair, estarão eles mais vivos do que nunca. Pode confiar. Para onde gostaria de te levar agora, acontece tal qual o dito popular: o que não mata, fortalece.

Pronta? Então vamos lá.

O que o corpo não aguenta mais? Gosto do modo como o filósofo paulista Peter Pál Pelbart em seu "Biopolítica", responde a essa pergunta:

O corpo não aguenta mais tudo aquilo que o coage, por fora e por dentro. Por exemplo, o corpo não aguenta mais o adestramento civilizatório que por milênios se abateu sobre ele, como Nietzsche o mostrou exemplarmente em Para a genealogia da moral. Ou mais recentemente, o sociólogo Norbert Elias, quando descreveu de que modo aquilo que chamamos de civilização é resultado de um progressivo silenciamento do corpo; dos seus ruídos, impulsos, movimentos, arrotos, peidos, etc. Mas também o que o corpo não aguenta mais é a docilização que lhe foi imposta pelas disciplinas nas fábricas, nas escolas, nos exércitos, nas prisões, nos hospitais, pela máquina panóptica. (Pelbart, 2007)

Diante do que Pelbart nos coloca, Eleonora, eu te pergunto: como agir a fim de encontrar a potência em um corpo disciplinado, domesticado, silenciado? Como desestruturar um corpo enrijecido pela disciplina, docilizado pela aparência e silenciado pelas diversas formas de poder? Como encontrar a potência de um corpo que sofre? Que não aguenta mais?

Eu te perguntei, mas deixo Lapoujade responder primeiro: "a primeira condição consiste em sentir este sofrimento, o "Eu sinto" que é um "Eu não aguento mais", pois esta exposição ao fora é insuportável. O corpo deve primeiro suportar o insuportável, viver o inviável. É o sentido do corpo sem órgãos em Deleuze: que o corpo passe por estados de torção, de dobramentos que um organismo desenvolvido não suportaria" (Lapoujade, 2002, p.87).

Esse "organismo desenvolvido" do qual fala Lapoujade, ao citar Deleuze, é também o que define um corpo com aquele que não aguenta mais. O organismo é um "estrato", uma forma de poder sobre o corpo que, como dizem Deleuze e Guattari 
em "28 de novembro de 1947 - como criar para si um corpo sem órgãos?", junto à significância e à subjetivação, formam o conjunto dos estratos que impõe ao corpo "formas, funções, ligações, organizações dominantes e hierarquizadas, transcendências organizadas para extrair um trabalho útil" (Deleuze e Guattari, 2012, p.24), ou seja, o que os estratos querem é domar o corpo, torna-lo dócil e disciplinado para assim continuar a sua dominação sobre ele. Para (des)estratificar um corpo, para (des) organiza-lo e, assim, conduzi-lo à experimentação, Deleuze e Guattari sugerem a criação de um corpo sem órgãos, corpo este que se opõe ao "juízo de Deus, o sistema do juízo de Deus, o sistema teológico", que é precisamente "a operação Daquele que faz um organismo, uma organização de órgãos que se chama organismo" (Deleuze e Guattari, 2012, p.24). Estratificado pelo Juízo de Deus e desejoso por libertar-se dele, o Corpo sem Órgãos grita:

Fizeram-me um organismo! Dobraram-me indevidamente! Roubaram meu corpo! O juízo de Deus arranca-o de sua imanência e lhe constrói um organismo, uma significância, um sujeito. É ele o estratificado. Assim, ele oscila entre dois polos: de um lado, as superfícies de estratificação sobre as quais ele é rebaixado e submetido ao juízo, e por outro lado, o plano de consistência no qual ele se desenrola e se abre à experimentação. [...] Combate perpétuo e violento entre o plano de consistência, que libera o $\mathrm{CsO}$, atravessa e desfaz todos os estratos, e as superfícies de estratificação que o bloqueiam ou rebaixam. (Deleuze e Guattari, 2012, p.25)

Eleonora, ainda seguro a sua mão? Já estamos saindo do túnel, percebe?

Oscilar entre os estratos e o plano de consistência: esta é a dose necessária de prudência para a criação de um corpo sem órgãos, esta é o modo encontrado por Deleuze e Guattari para encontrar a potência de um corpo que sofre. E são eles quem nos alertam: "não se atinge o CsO e seu plano de consistência desestratificando grosseiramente" (Deleuze e Guattari, 2012, p. 26) assim como não se atinge uma ferida sutil, sem se proteger da ferida grosseira. Bravejam ainda Deleuze e Guattari:

Liberem-no (o CsO) com um gesto demasiado violento, façam saltar os estratos e vocês mesmos se matarão, encravados num buraco negro, ou mesmo envolvidos numa catástrofe, ao invés de traçar o plano. O pior não é permanecer estratificado - organizado, significado, sujeitado - mas precipitar os estratos numa queda suicida ou demente, que os faz recair sobre nós, mais pesados do que nunca. (Deleuze e Guattari, 2012, p.27)

Lapoujade nos ensina: "se fechar para se abrir é o paradoxo da prudência" (Lapoujade, 2002, p.89), Deleuze e Guattari fazem coro: é preciso traçar o plano, criar o programa, pois que programa é o "motor de experimentação" (Deleuze e Guattari, 2012, p.14).

Pronto. Saímos do túnel. Aqui estamos. Solto agora a sua mão e olho para você. Seu corpo, assim como o meu, está alegremente ferido e quer me dizer algo, algo que ele aprendeu nesta árdua travessia, eu o escuto e deposito aqui suas palavras.

Seu corpo me diz que, inspirado pelo uso que Deleuze e Guattari fazem da palavra programa e que, atento a si próprio, quer experimentar ser corpo sem órgãos quando ele já é corpo que não aguenta mais, você sugeriu para ele a prática de um "procedi- 
mento composicional específico" a que chamou de "programa performativo":

a prática do programa cria corpos e relações entre corpos, deflagra negociações de pertencimento; ativa circulações afetivas impensáveis antes da formulação e execução do programa. Programa é motor de experimentação psicofísica e política. Ou para citar palavra cara ao projeto político e teórico de Hanna Arendt, programas são iniciativas. Muito objetivamente, o programa é o enunciado da performance: um conjunto de ações previamente estipuladas, claramente articuladas e conceitualmente polidas a ser realizado pelo artista, pelo público ou por ambos sem ensaio prévio. [...]. É este ensaio programa/enunciado que possibilita, norteia e move a experimentação. (Fabião, 2013)

Você diz ainda que "através da realização de programas, o artista desprograma a si e ao meio. Através de sua prática acelera circulações e intensidades, deflagra encontros, reconfigurações, conversas" (Fabião, 2013)

Desde que eu escutei pela primeira vez estas palavras, não pude mais esquecê- las e tenho feito uso dessa prática do programa performativo a cada vez que sinto necessidade de me (des)estratificar, me (des)habituar, de escovar a contrapelo como você diz, de expor meu corpo ao sofrimento e ao regime das feridas sutis como diz Lapoujade e com a devida dose de prudência para não esquecer de Deleuze e Guattari.

Pois o que foi o encontro entre o meu corpo e o corpo da cidade naquele dia 03 de julho de 2015 quando da execução do programa performativo Vodu, senão a experimentação psicofísica e performativa de um corpo que se abre em feridas para não se esquecer da sua condição de ser corpo? O que foi a execução do programa Vodu senão a deflagração de encontros improváveis e a ativação de circulações afetivas impensáveis como a que se deu entre o meu corpo e o seu corpo, entre o meu corpo e o corpo da rua?

Criar o programa, Eleonora, para nos protegermos das feridas grosseiras e nos abrirmos às feridas sutis, criar o programa para fazer corpo sem órgãos deste e neste corpo que não aguenta mais, criar o programa para fazer corpo com o corpo da cidade.

Eu crio Figuras e programas performativos como forma de lidar com as minhas feridas. E você, minha querida? Me diga: não fossem as feridas teria você começado a performar? Não fossem as feridas teria você necessidade de criar programas performativos? Quais foram as feridas que te tiraram do palco e te levaram às ruas?

Pergunto por que nossas histórias de vida se assemelham em alguns aspectos. Você fazia teatro assim como eu, assim como eu você atuava em edifícios teatrais e construía uma carreira como atriz, mas num dado momento você começa a performar nas ruas do Rio de Janeiro e está aí desde então. Me pergunto o que te levou a performar na cidade, o que te levou a descer do palco e fincar os pés na rua? Ao ler o seu "Ações Cariocas, 7 ações para o Rio de Janeiro", encontro pistas para estas perguntas. Ali você diz que:

para circular novas velocidades e afetos, para realizar novas relações performativas e conexões com a cidade maravilhosa onde nasci e cresci, para criarmos corpo juntas, foi imprescindível abandonar os locais ditos 'apropriados' para a fruição artística. Em coro com tantos outros performers, atores e artistas de rua, 
foi imprescindível investigar as condições de possibilidade da arte fora da caixa (preta do teatro ou branca da galeria) e fora de qualquer moldura institucional artística" (Fabião, 2010)

E logo em seguida você diz o que te levou a conceber e performar esta série de ações cariocas nas ruas da sua cidade:

primeiro e acima de tudo me sentir bem outra vez numa cidade onde estava me
sentindo mal e intoxicada pelos mais variados Venenos, Dráculas, Cotonetes, Pa-
lhaços, Bebezões, Super-heróis da liga da Justiça, a banda podre da polícia e os
políticos envolvidos com crime e corrupção. [...] Ações Cariocas é um projeto
de desintoxicação: expurgar as toxinas do medo via contato, diálogo, fricção.
Uma re-apropriação do corpo e da cidade, um através do outro. Ou melhor, uma
apropriaçãa do corpo e da cidade como corpo. Ambos corpos em processo de
formação contínua já que a cidade nos faz e nós fazemos a cidade. (Fabião, 2010)

Evoco aqui suas palavras, Eleonora, porque gosto muito de relê-las e releio seus escritos não para melhor compreendê-los, mas justamente por já tê-los compreendido bem. Fechar os olhos e ouvir a sonoridade de palavras como: desintoxicação, contato, diálogo, fricção, re-apropriação, ouvir frases como "expurgar as toxinas do medo" e "apropriação do corpo e da cidade como corpo" é de um amigamento tremendo, é amizade o que sinto, e essa amizade se manifesta de diversas maneiras como quando o seu corpo de palavras da a mão ao meu corpo Figura e assim, de mãos atadas, eles seguem fortes e afirmativos, rumo ao encontro com outros corpos que nos são muito caros e que exigem de nós muito trabalho e atenção: o corpo do outro e o corpo da cidade.

Estamos vivendo momentos difíceis e sombrios em nossa cidade e País, imagino que você, assim como eu, deve estar bastante chateada com tudo o que está acontecendo. Não sei se te conforta o que vou dizer, minha querida, mas não é pouco efetivo e transformador o que suas ações e palavras destinam ao mundo. Falo por mim, mas sinto que o mesmo vale para muitos outros. Você deu palavras a gestos que eu não saberia nomear, sugeriu caminhos quando eu duvidei do sentido, me conduziu por mãos hábeis e muitas vezes invisíveis à arte da performance e o fez com doçura e consistência, amorosidade e bravura e, hoje, você caminha ao meu lado na insistência dos passos que desejam persistir no mundo. Pois se trata disso não é, minha querida? Enfrentar, persistir, não ceder, aderir e também resistir.

Que os nossos corpos sobrevivam, é o que desejo para nós.

Com amor,

Flávia Naves

\section{Referências}

DELEUZE, G.; GUATTARI, F. Mil Platôs: capitalismo e esquizofrenia 2, vol.3. São Paulo: Editora 34, 2012.

FABIÃO, Eleonora. Ações cariocas: 7 ações para o rio de janeiro. Cavalo Louco: v. 8, 
2010, p. 14-18.

Performance e teatro: poéticas e políticas da cena contemporânea. In: ARAÚJO, Antônio; AZEVEDO, José Fernando; TENDLAU, Maria. (Org.). Próximo ato: teatro de grupo. São Paulo: Itaú cultural, 2011.

Programa Performativo: o corpo em experiência. In: ILINX Revista do LUME (Núcleo interdisciplinar de pesquisas teatrais da Unicamp: \#4, 2013) p 1-11. Disponível em: http://www.cocen.unicamp.br/revistadigital/index.php/lume/ article/view/276. Acesso em: setembro de 2016.

LAPOUJADE, Davi. O corpo que não aguenta mais. In: LINS, Daniel e GADELHA, Sylvio (orgs.). Nietzsche e Deleuze: que pode o corpo. Rio de Janeiro: Relumé Dumará, Fortaleza: Secretaria da Cultura e Desporto, 2002.

PELBART, Peter Pál. Biopolítica. In: Revista Sala Preta, v. 7. São Paulo: PPGAC; Universidade de São Paulo, 2007. Disponível em: http://www.revistas.usp.br/salapreta/ article/view/57320. Acesso em: set. 2016.

PESSANHA, Juliano Garcia. Testemunho Transiente. São Paulo: Cosac Naify, 2015.

Recebido em: 30/09/2016 Aprovado em: 13/11/2016 